\title{
GEOPROCESSING TECHNIQUES APPLIED TO THE STUDY OF THE DYNAMICS OF LAND USE AND LAND COVER AT SMALL WATERSHEDS
}

\author{
Mario Valerio Filho \\ Osvaldo Coelho Pereira Neto \\ INPE- Instituto Nacional de Pesquisas Espaciais \\ 12227-010 - São José dos Campos, CP. 515 \\ São Paulo - Brazil \\ Fax: +55123218743
}

\begin{abstract}
This study compares the land use support capacity of an agricultural region in Northern Paraná State (Brazil) for the year 1993 with that of 1980, using a GIS and an Image Analysis System. The methodology consists of three steps, namely: 1. A land use and land cover map was obtained using digital image processing techniques applied to images from 1993 and by visual interpretation of the resulting product. An available survey for 1980 was also used. 2. An agricultural land suitability map was obtained by cross-checking soil limiting factors. Given the importance of the slope factor, a more detailed analysis was performed. 3 . The land use/land cover and agricultural land suitability maps were integrated in order to generate land use adequacy maps for 1980 and 1993, followed by an analysis of the adequacy for this period. This analysis proved to be very useful for rural activities, because it allows the detection of areas with high erosion risks, and therefore reduces the efforts for conservation control.
\end{abstract}

\section{INTRODUCTION}

The intensive soil occupation for agricultural use, without considering its support capacity, is highly responsible for the soil erosion and degradation processes and its negative results for water resources. The support capacity of soils can be obtained by the determination of the Agricultural Land Suitability, that allows a technical and economical evaluation for the adequate agricultural use of soils. The availability of information concerning the Agricultural Land Suitability allows the monitoring of agricultural areas, referring to its use, and specially to the discrepancies related to its bad use. This allows agricultural planning at regional level and even at small watersheds. In order to perform this analysis, the land use/land cover, its survey is necessary and remote sensing techniques have proved to be useful tools for this work, as it was shown, by several authors, among others, by [7], [5], [6], and [3].

To obtain information on Agricultural Land Suitability the integration of environmental variables (such as edaphic conditions, relief, climate) is needed, and presently GIS allows the manipulation of different databases, and to cross data. An example of this, is the evaluation of Agricultural
Land Suitability, that consists in the comparison of land use maps with the recommendations for its proper use. These data manipulation operations are possible by the use of joint remote sensing and GIS techniques, as presented by [8], [1], [2]. In this frame, the objective of our study is to present a methodology using both remote sensing and GIS techniques for the analysis of adequateness of land use/land cover, as well as the of its dynamics.

\section{AREA UNDER STUDY}

The area under study is located in Paraná State (Brazil) and has the following coordinates: S $23^{\circ} 16^{\prime} 30^{\prime \prime}$ to $23^{\circ} 22^{\prime} 30^{\prime \prime}$ and $\mathrm{W} 51^{\circ} 11^{\prime} 40^{\prime \prime}$ to $51^{\circ} 23^{\prime} 30^{\prime \prime}$. The relief is made up of hills with flat tops and long slopes in almost the entire area. The original vegetation was a Subperennial Forest now covering only $4 \%$ of the area.

\section{MATERIALS AND METHODS}

In order to perform this study the following materials were used: TM/Landsat images, Topographic maps at 1:50,000 scale, the image analysis system SITIM/INPE and SGI/INPE. The TM-Landsat data were submitted to image processing techiniques (geometric correction and digital enhancement) and color composites were obtained. The visual analysis of these products allowed the elaboration of land use/land cover map for 1993. The 1980 map was already available, only the legend was adapted to fit with the 1993 map. To obtain the map on Agricultural Land Suitability, initially we made a map of the slopes, using an analogical abacus, applied manually to the cartographic base (the topographic maps used have a contour interval of $20 \mathrm{~m}$ ). In parallel to that, a slope map was obtained using the software available at SGI/INPE. As a second step, the map of Agricultural Land Suitability was obtained by the integration of environmental parameters such as: soil type, slope, climate and limiting factors like deficiency of fertility, water deficit, oxygen deficit (water stress), erosion risk and impediment to mechanization. For each one of these parameters an Information Plane (IP) was created, that were 
afterwards integrated by SGI/INPE to obtain the map of Agricultural Land Suitability. This map was crossed with the land use/land cover maps to evaluate those areas of discrepancies (where land use is not compatible with the technical recommendations of the Agricultural Land Suitability map) and its quantification for the timeframe analyzed. All these data manipulation operations were made at the SGI/INPE environment.

\section{RESULTS AND DISCUSSION}

The analysis and interpretation of TM/Landsat products as color composites TM 5/ Red, TM/ Green, TM3/ Blue and $\mathrm{TM} 4 \mathrm{R} 3 \mathrm{G} 5 \mathrm{~B}$, as well as information obtained during field work, allowed the elaboration of the land use/land cover map. We observed that, during the interpretation of the color composites, that the TM 4R $3 \mathrm{G} 5 \mathrm{~B}$ composite was most informative, agreeing with [7]. Table 1 presents the quantitative results of land use/land cover classes for the period under study, showing mainly the decrease of areas with perennial cultures and pastures and the increase of annual cultures. The class "bare soil" that shows up only in 1993 , is essentially associated with those areas to be used for summer crops.

Table 1 - Quantitative assessment of land use and land cover classes in 1980 and 1993.

\begin{tabular}{|l|r|r|r|r|}
\hline \multirow{2}{*}{$\begin{array}{l}\text { Land Use } \\
\text { Classes }\end{array}$} & \multicolumn{2}{|c|}{1980} & \multicolumn{2}{c|}{1993} \\
\cline { 2 - 5 } & Area (ha) & Area (\%) & Area (ha) & Area (\%) \\
\hline Urban areas & 209.5 & 1.7 & 316.5 & 2.6 \\
\hline Lots & 38.6 & 0.3 & 324.3 & 2.7 \\
\hline $\begin{array}{l}\text { Summer } \\
\text { crops }\end{array}$ & 5464.4 & 46.2 & 6835.0 & 57.6 \\
\hline $\begin{array}{l}\text { Perennial } \\
\text { crops }\end{array}$ & 2184.4 & 18.4 & 714.6 & 6.2 \\
\hline \begin{tabular}{l} 
Pasture \\
\hline $\begin{array}{l}\text { Floodplain } \\
\text { vegetation }\end{array}$
\end{tabular} & 2894.7 & 24.4 & 1678.3 & 14.2 \\
\hline $\begin{array}{l}\text { Reforestation } \\
\text { Natural } \\
\text { vegetation }\end{array}$ & 163.3 & 2.4 & 129.8 & 1.1 \\
\hline $\begin{array}{l}\text { Water bodies } \\
\text { Bare soil }\end{array}$ & 15.4 & 0.1 & 27.2 & 0.2 \\
\hline Total & 11820.4 & 100.0 & 11820.4 & 100.0 \\
\hline
\end{tabular}

The slope map obtained by the SGI/INPE software did not show much coherence with the topographic changes, if compared quantitatively with the map obtained by the analogical abacus. These results confirm the findings from [4], who states that those areas with a homogeneous and flat relief are less sampled due to a larger distance among contour lines. The integration of environmental parameters, as presented before, allowed to obtain the map of Agricultural Land Suitability. Therefore we created a file of rules that includes all possible combinations of the parameters considered. As a result of this integration, we came up with three groups of Agricultural Land Suitability: Group I - areas suitable for summer and perennial crops; Group II - areas regularly suitable for summer and perennial crops; Group III - inappropriate areas for summer/perennial crops, but suitable for pasture and reforestation The other groups (II, IV and VI), that normally occur on the Agricultural Land Suitability maps did not show up in the area under study.

After crossing the Agricultural Land Suitability map and the land use/land cover maps, it was possible to characterize those areas of discrepancy in the area under study, for both dates. Table 2 presents the results obtained from those areas showing land use patterns that are compatible with the Agricultural Land Suitability map and those that are under or over-used in 1980. (When lands are used below its support capacity, these areas are considered as "under use", while for those lands that are used for activities beyond its support capacity, they are named as "over use") One can observe that, for this date, $81.16 \%$ of the area was used within the limits of its support capacity and just 16.61\% incompatible, that were partially responsible for soil degradation processes.

Table 2 - Quantitative assessment of land use class adequacy in 1980.

\begin{tabular}{|l|r|r|}
\hline Adequacy Classes & Area (ha) & Area (\%) \\
\hline Urban Areas & 209.56 & 1.77 \\
\hline Lots & 038.62 & 0.33 \\
\hline Water bodies & 015.41 & 0.13 \\
\hline Under use & 5483.56 & 46.39 \\
\hline Compatible use & 4110.12 & 34.77 \\
\hline Over use & 1963.19 & 16.61 \\
\hline Total & 11820.46 & 100.00 \\
\hline
\end{tabular}

At Table 3 the results for 1993 are shown. For this date, $68.07 \%$ of the area is being adequately used and $26.28 \%$ is incompatible with the land support capacity. This indicates an increase of discrepant land use areas by about $10 \%$ for the timeframe under study.

In a feasibility analysis for this timeframe, (Table 4) we concluded that $7.23 \%$ of the area changed activities to other less intensive ones, while for $29.78 \%$ of the area, activities were intensified. On the other hand, $44.14 \%$ were stable, in a good state of conservation. This figure should be added by $16.53 \%$ that changed from "under use" to "compatible use". Being so, $60.67 \%$ of this region are used within the tolerance limits. Special attention should be paid to those areas of "stable over use" (13.20\%) and those of "implanted over use" $(13.25 \%)$, because these are critical areas where the 
agricultural activities increase the soil degradation processes and consequently increase the sediment load in the drainage of this small watershed

Table 3 - Quantitative assessment of land use class adequacy in 1993.

\begin{tabular}{|l|r|r|}
\hline Adequacy Classes & Area (ha) & Area (\%) \\
\hline Urban Areas & 315.55 & 02.68 \\
\hline Lots & 324.76 & 02.75 \\
\hline Water bodies & 027.20 & 00.22 \\
\hline Under use & 2891.38 & 24.46 \\
\hline Compatible use & 5155.35 & 43.61 \\
\hline Over use & 3105.22 & 26.28 \\
\hline Total & 11820.46 & 100.00 \\
\hline
\end{tabular}

Table 4 - Quantitative assessment of land use adequacy in the time frame.

\begin{tabular}{|l|r|c|}
\hline \multicolumn{1}{|c|}{ Classes } & Area (ha) & Area (\%) \\
\hline Stable under use & 2093.33 & 17.71 \\
\hline Stable compatible use & 3124.19 & 26.43 \\
\hline Stable over use & 1560.62 & 13.20 \\
\hline $\begin{array}{l}\text { Compatible use to under } \\
\text { use }\end{array}$ & 480.96 & 4.07 \\
\hline $\begin{array}{l}\text { Under use to compatible } \\
\text { use }\end{array}$ & 1953.94 & 16.53 \\
\hline Removed over use & 373.25 & 3.16 \\
\hline Implanted over use & 1565.64 & 13.25 \\
\hline Urban area & 316.55 & 2.68 \\
\hline Lots & 324.76 & 2.75 \\
\hline Water bodies & 27.20 & 0.22 \\
\hline Total & 11820.46 & 100.00 \\
\hline
\end{tabular}

\section{CONCLUSIONS}

The methodology proposed in this study, using both remote sensing and GIS techniques, is an important tool for the survey, analysis and integration of environmental parameters and for the quantification of areas of discrepancy, referring to land use/land cover at small watersheds. This analysis is of high interest for those activities in the rural areas, because it allows to detect areas of erosion risks and therefore reduces the efforts for environmental control.

\section{REFERENCES}

[1] G. Bocco; J. Palacio and C.R. Valenzuela. Gully erosion modeling using GIS and geomorphologic knowledge, ITC Journal (3): 253-261, 1990.

[2] A. G. Castro. Técnicas de sensoriamento remoto e sistemas de informação geográfica no estudo integrado de bacias hidrográficas. Msc. Thesis, INPE, São José dos Campos, Brazil 1992, 112 p.

[3] S. E. Franklin, and Wilson B.A. A tree-stage classifier for remote sensing to monitor environments. Photog.. Engin. and Rem. Sensing. (58): 449-454. 1992.

[4] W.Gomes. Amostragem e interpolações em modelos digitais de terreno. Msc. Thesis, INPE, São José dos Campos. INPE, 1989, 111 p. ( INPE-5041-TDL/404).

[5] S. A. F. Pinto, M. Valerio Filho and G. J. Garcia. Utilização de imagens TM/Landsat na análise comparativa entre dados de uso da terra e de aptidão agrícola. Revista Brasileira de Ciência do Solo, (13): 101-110, 1989.

[6] J. R. G. Townshend. Land cover. International Journal of Remote Sensing. (13): 1319-1328. 1992.

[7] L. J. Trolier and W. R. Philipson. Visual analysis of Landsat Thematic Mapper images for hyrologic land use and cover. Photogrammetric Engineering and Remote Sensing, $52(9): 1531-1538,1986$.

[8] C. L. Wilson, F. J. Thomson. Integration and manipulation of remote sensing and other data in GIS. In: Proceeding of the VIII Pecora Symposium, Sioux Fall, SD, 1982, p. 303-317. 